\title{
Talebe Bağlı Video Servisleri Çağında Netflix Etkisi
}

\author{
SEDAT ÖZEL* \\ sedatozel@kocaeli.edu.tr \\ ORCID ID: 0000-0002-8280-1930
}

\begin{abstract}
Öz: Video akış teknolojisinin ortaya çıkması ve gelişmesi, geleneksel televizyon üretim ve tüketim biçimlerinde güçlü bir değișimin sebebi olmuştur. İzleyici için aktif bir izleme sürecinden sıklıkla bahsedilmekle ayrıca televizyon içeriğinin dağıtımında yeni olanaklar, yeni iş modellerine vurgu yapılmaktadır. Çalışma bu iş modellerinden biri olan OTT'ye odaklanmakla birlikte, değişimin temel kodlarını kavramsal bir analize bağlı kalarak incelemektedir. Değişimi anlatmak için Netflix etkisi deyimi sıkça kullanılır. Bu bağlamda Netflix’in nasıl öne çıktığına dair tespitler bir noktada televizyondaki değişimin de somut örneğidir. Netflix’in, izler kitlenin parçalı yapısına uygun içerik katalogları geliştirmesi, standart televizyon akışına karşı kendi yayın planını uygulaması ve bunlarla ilişkili tıkınırcasına izleme (binge watching) davranışını destekleyen stratejileri ile küresel olarak güçlenmiştir.
\end{abstract}

Anahtar kelimeler: Video akıs, OTT, Talebe bağh video, Tikınırcasına izleme, Netflix

\section{Giriş̧}

Yeni medyanın üzerinde yükseldiği geniş bant ağ teknolojisindeki ilerlemelere bağlı olarak gelişen ve çeşitlenen hizmetlerden biri kuşkusuz video akışlarıdır (video streaming). WEB 2.0 ile İnternette kendine kalıcı bir yer bulan video akışları, TV üretim, dağıtım ve tüketim biçimlerinde de büyük değişimlere neden olmuştur. Günümüzde hala dünyanın büyük bir kısmında geleneksel olarak adlandırılan yayın teknikleri ile TV akışları izleyicilere ulaşsa da yüksek hızlı ağların gelişen ve genişleyen yapısı internetin bir video dağıtım alt yapısı olarak işlevselliğini gün geçtikçe artırmaktadır. Buna bağlı şekilde sunulan farklı hizmetler, bilinen anlamıyla TV teriminin ifade ettiğinin ötesinde bir oluşuma işaret etmektedir. Böylesi bir süreçte TV artık sadece, bir kurumsal yayıncılık sürecine bağlı olarak önceden belirlenmiş bir yayın planı çerçevesinde, belli içeriklerin art arda sıralandığı, hava dalgaları üzerinden (uydu, karasal vs.) aktarılan video işaretlerinin bu işaretleri göstermeyi sağlayan belli bir ekrandan izlenme eylemi ile ilişkili değildir. Ekranların mekân bağımsız, içeriklerin ise zaman bağımsız olduğu yeni bir dönemden bahsedilmektedir.

* Doç. Dr., Kocaeli Üniversitesi, İletişim Fakültesi. 
Geleneksel yayıncılık refleksi sabit bir takvim içinde program ve reklam serileri oluşturmaktır. Williams tarafından akış (flow) kavramı ile açıklanan bu yapıda, kabaca bir ifadeyle TV programlarına erişim uzmanlar tarafından planlanır ve takvime işlenir. Planlanan bu akış, neyin ne zaman yayınlanması gerektiğine dair anlamlı kararlar bütünüdür ve sabit olan bu planlama etrafında TV izleme deneyimi düzenlenir. İzler kitlenin planlama üzerinde sınırlı bir etkisi vardır ki bu, belirli bir zamanda izlemek ya da izlememek ve kanalı değiștirmek gibi eylemlerdir. ${ }^{1}$

Teknolojik ilerleme ve entegrasyon, TV alıcılarının merkezde olduğu bir donanım matrisinin, sayısal yetenek ve biçimleri ile TV mantığını içeren bilgisayarlara doğru genişlemesine neden olmuştur. TV’ye özgü medya biçimleri ile yeni medya biçimleri arasında bir köprü görevi gören bu çok seçenekli donanım ortamında kullanıc1lar, genellikle daha aktif seçim yapma imkanına sahip oldukları dijital etkileşimin endüstriyel mantığına doğru yönelim göstermektedirler. ${ }^{2}$ Yeni endüstri ortamında "Akış" (Streaming), artık tüketim süreçlerinin belirgin terimidir çünkü çok uluslu teknoloji şirketleri tarafından yönetilen, algoritma ve doğrusal olmayan yayın planlama kullanımı ile geleneksel TV'nin üretim, dağıtım ve alımlama uygulamalarını (karasal, kablo ve uydu yayıncılığı) temelden değiştiren, yeniden şekillendiren iletim biçimini temsil etmektedir. ${ }^{3}$

Artık TV izlemenin gittikçe karmaşık, kasıtlı ve bireysel bir eyleme dönüştüğü, her yerde ve her zaman gerçekleşen aktif bir süreç haline geldiği bir noktada olduğumuz ileri sürülmektedir. Ancak bu tür söylemlerin izleyicilerdeki yansımayı çok da detaylı bir şekilde incelemediği, gerçek uygulamalar ve deneyimlerden ziyade dijital teknolojilerin izleyiciler için yarattığı fırsatlara ve kitle davranışı ile ilgili beklentilerin genelleştirilmesine dayandığı eleştirisi yapılır. ${ }^{4}$ Yine de yeni medya türleri geliştirildikçe içerik ve izleyici davranışlarında bir değişim olduğu göz ardı edilmez. Ayrıca yeni medya, kullanıcıların ihtiyaçlarını karşılayan farklılaştırılmış içerikler sağlayarak geleneksel medyayı da tamamlayan bir rol üslenir. ${ }^{5}$

TV kuruluşları, insanların gözlerini ayıramayacakları ekranları ortaya koyan iş akışlarını hala sürdürmekle birlikte çoklu platformlar ile daha fazla ekrana kavuşmuştur. ${ }^{6}$ Time Warner'in eski CEO’su Jeff Bewkes'e göre dijital devrim interneti TV’ye çevirmek anlamına geliyor. Bewkes, biraz genelleme ile cihazlar arasındaki farkları görmezden gelerek tabletlerin ve akıllı telefonların sadece daha küçük, taşınabilir

\footnotetext{
1 Fenwick McKelvey ve Robert Hunt, "Discoverability: Toward a Definition of Content Discovery Through Platforms", Social Media + Society, 5/1 (2019), s.2.

2 Christopher M. Cox, "Programming - Flow in the Convergence of Digital Media Platforms and Television", Critical Studies in Television, 13/4 (2018), s.443.

3 Kevin Sanson ve Gregory Steirer, "Hulu, Streaming, and the Contemporary Television Ecosystem", Media, Culture \& Society, 41/8 (2019).

4 Alexander Dhoest ve Nele Simons, "Still 'Watching' TV? The Consumption of TV Fiction by Engaged Audiences", Media and Communication, 4 (2016), s.177.

5 Shinjae Jang ve Minsoo Park, "Do New Media Substitute for Old Media?: A Panel Analysis of Daily Media Use”, Journal of Media Economics, 29/2 (2016).

6 Inge Ejbye Sørensen, "The Revival of Live TV: Liveness in a Multiplatform Context”, Media, Culture \& Society, 38 (2015), s.394.
} 
TV’ler olduğunu ileri sürmüştür.7 Günümüzde TV artık hem sektörel hem de bilimsel terminolojide WEB TV, IPTV, OTT, VOD gibi terimler üzerinden değerlendirilmektedir. İnternetin yayılmasına paralel bir şekilde artan TV’nin çöküşüne dair söylentiler büyük ölçüde abartılmış olsa da gelişmiş ülkelerdeki TV endüstrisinde değişim, TV’nin bir ortam ve kültürel bir form olarak yeniden şekillendiğine işaret etmektedir. Bu yüzden 200 milyona yaklaşan abone sayıları ile Netflix ve Amazon gibi yeni oyuncular küresel TV piyasasının önemli figürleri haline gelmiştir. ${ }^{8}$

Araştırma farklı terimler ve kavramsal yaklaşımlarla ele alınan gelişmelere ama özellikle de son yıllarda yükselen OTT iş modellerine odaklanmaktadır. Bir çevrim içi DVD dağıtım firmasından küresel OTT servisine evirilen Netflix, talebe bağlı video hizmetlerine dayalı geliştirdiği iş modeliyle üretim-tüketim ekseninde günümüzde yaşanan değişimin öncüsü konumundadır. Çalışma bu varsayımdan hareketle değişenin ne olduğunu ve Netflix’in bu değişimde nasıl öne çıktığını ortaya koymayı amaçlamaktadır. Bunun için öncelikle akış teknolojileri ve çevrim içi televizyon uygulamalarını daha kesin bir şekilde tanımlamak gerektiği düşünülmektedir. Özellikle IPTV sistemleri ile OTT servislerinin iç içe geçmiş özellikleri, bu iki uygulama biçiminin çoğu zaman birbirinden ayrılmasını güçleştirmektedir. İki yapının da talebe bağlı video desteği sunması, bu güçlüğe temel neden olarak görülmektedir. Bu nedenle çalışmanın ilk fazında teknolojik bir gelişme olan akış ve buna bağlı ortaya çıkan uygulamalar ele alınmaktadır. Öte yandan çalışmanın odak noktasını oluşturan OTT servislerinin çekirdek özelliği olan talebe bağlı video hizmetlerinin, OTT servislerinin etkinliğini artırmasında dolayısıyla da pazar dinamiklerinde meydana gelen değişimde aktif rol oynadığı düşünülmektedir. Bu nedenle çalışmanın ikinci fazında talebe bağlı video hizmetleri ve etkileri tartışmıştır. Çalışmanın son fazında ise Netflix'in öne çıkmasına neden olan etkenler incelenmiştir. Çalışmanın dayand1ğ1 varsayım ve argümanlar kavramsal bir tartışmaya dayanak oluşturduğu için, öncül çalışmalarda farklı şekillerde ele alınan anahtar ifadeler üzerinden bir literatür taraması gerçekleştirilmiştir.

\section{TV Yayıncılığında Video Akışları (Streaming) ve Çevrim İçi TV Uygulamaları}

Bazen yavaş ve uzun soluklu bir süreç olsa da teknoloji, TV deneyimi ve yayıncılar ile izleyiciler arasındaki iliş̧i sürekli değişmektedir. En az iki algılanabilir devam eden gelişme çizgisi bu bağlamla ilgilidir. Birincisi, güç ve kontrolün gelişmekte olan bir endüstriye kayması. İkincisi, TV endüstrisinin, bilgisayar ve internet kullanımı ile ilişkili ağlara ve içeriğe açılma olanakları. ${ }^{9} \mathrm{Bu}$ değişimi açıklamak için sıkça kullanılan yaklaşımlardan biri olan ikame teorisine göre, yeni medya mevcut medyayı ikame edebilmektedir çünkü yeni sunulan ile mevcut medya içeriğinde önemli

7 Jang ve Park, "Do New Media".

8 Michael L. Wayne, "Netflix, Amazon, and Branded Television Content in Subscription Video On-Demand Portals", Media, Culture \& Society, 40/5 (2018), s.725.

9 Hallvard Moe, “Television, Digitalisation and Flow: Questioning the Promises of Viewer Control, Digital Utopia in the Media: From Discourses to Facts. A Balance", Proceedings of the III International Conference on Communication and Reality, Haz., Pere Masip ve Josep Rom, Barcelona: Facultat de Cièències de la Comunicació Blanquerna, 2005, s.280. 
bir çakışma bulunmaktadır. Hatta Shinjae ve Minsoo $^{10}$ internetin gelişimi ile ortaya çıkan çevrim içi gazete ve IP TV'nin içerik olarak geleneksel gazete ve kablolu yayıncllıktan önemli bir farkı olmadığını ileri sürmektedir.

Ancak içeriğin dağıtım süreci düşünüldüğünde değişime daha fazla önem yükleyenler çoğalmaktadır. Örneğin video aktarım biçimleri çoğaldıkça ve geliştikçe, TV içeriğinin dağıtım mantığında da değişimler meydana gelmiştir. Ayrıca bu sadece dağıtım mantığı ile sınırlı değildir. Netflix, Hulu ve Amazon Prime Video gibi talebe bağlı video platformlarına abone olan kullanıcılar, algoritma etkisiyle seçilmiş içerik kataloglarında, etkileşim ile karakterize edilen farklı bir izleme davranışına alışmıştır. Herhangi bir Netflix abonesinin bildiği üzere platformların içeriği sunma ve filtreleme yolu, esas olarak doğrusal yayın akışından farklıdır. Bu farklılık gözetildiğinde TV’nin bir veri tabanı formuna dönüştüğü ileri sürülür. ${ }^{11} \mathrm{Bu}$ dönüşümde ön plana çıkan ise video akışlarındaki (streaming) artan kabiliyettir.

Akış, 1990'larda yerel bir sürücüye dosya indirilmeden veya depolamaya gerek kalmadan medyanın "gerçek zamanlı" olarak internet üzerinden yayınlanmasına yönelik teknik bir süreci tanımlamak için kullanılmaya başlanmıştır. Alternatif olarak bu kelime bazen teknik iletim yöntemlerinden bağımsız bir şekilde, "talebe bağlı" hizmet biçimlerini de ifade eder. Ancak akış zamanla ve artan bir şekilde müzik, film ve TV sektörlerinde yaygınlaşan belirli bir medya hizmetini ifade eder hale gelmiştir. $\mathrm{Bu}$ hizmetlerin temel özellikleri internet protokolleri üzerinden büyük bir medya kataloğuna talebe bağlı erişim için abonelik ödemesi gibi görünmektedir ancak çoğu müzik akışının bu hizmetlerin ücretsiz sürümleri aracılı̆̆ıyla gerçekleştiği de göz önüne alınmalıdır. ${ }^{12}$

Akış ekseriyetle çevrim içi bir süreci temsil eder. Tüm veri paketleri internet üzerinden ve kullanıcının bilgisayarına ulaşmadan önce bile oynatmanın başladığ 1 hemen izlemeye ya da dinlemeye uygun çevrim içi ses ve video dosyalarının iletilme metodudur. Öte yandan basit anlamda bir bilgisayardan diğerine ses ve video aktarılması da medya akışı olarak tanımlanmaktadır. Ancak burada dikkat edilmesi gereken nokta, aktarım ve izleme ya da dinleme işinin aktarılan verinin niteliğine bağlı olarak zaman bağımsız olabilmesidir. Bu nedenle akış, "canlı" (live) ile "talep üzerine" (on demand) ayrımıyla betimlenir. ${ }^{13}$ Genellikle talebe bağlı akışlar daha çok tercih edilir. Bu tür video içeriği internet ortamında bulunur yani daha önceden kayıt edilmiş videolar bir noktada depolanmış durudadır ve internet ağları üzerinden eş zamanlı olarak küçük paketler halinde istemciye iletilir. Canlı video akışlarında ise gerçek zamanlı yayın (haber programları, konserler, spor etkinlikleri ya da bir TV kanalının yayın akışı) internet üzerinden verilmektedir ve "webcasting" olarak adlandırılır. Her iki şekilde de kullanıcılar dosyanın cihazlarına inmesini beklemeden

10 Jang ve Park, "Do New Media".

11 Ramon Lobato, "Rethinking International TV Flows Research in the Age of Netflix", Television \& New Media, 19/3 (2018), s.241.

12 Daniel Herbert, Amanda D. Lotz ve Lee Marshall, "Approaching Media Industries Comparatively: A Case Study of Streaming", International Journal of Cultural Studies, 22/3 (2019), s.351.

13 Sedat Özel, “Yeni Medya Çağında Radyoların Dönüşümü”, Akdeniz İletişim, 22 (2014), s.178. 
video dosyalarını oynatabilir. Böylece dosya indirmek için uzun bekleme süreleri ya da yetersiz disk alanı gibi problemler başta olmak üzere video ile ilişkili birçok sorunun üstesinden gelinmiş olunur. Sonuçta video içeriği gibi büyük dosyaları kısa sürede indirebilecek bağlantı hızına sahip olmayan istemci için akış yayıncılıkta bir dönüm noktası olmuştur. ${ }^{14}$

İnternette video akışları ile ortaya çıkan çevrimiçi TV, bireylerin izlemek, oynatmak veya duymak istedikleri şeyleri seçtikleri bağlamları içeren harekete geçirici eğlenceyi temsil eder. TV’nin böylesi bir yapıya geçişi beraberinde önemli varsayımları da getirmiştir. Bu varsayımlara göre akışa dayalı TV her yerde bulunabilir, isteğe bağlıdır ve her zaman kullanılabilir. Bununla birlikte tıkınırcasına izleme (binge) için yapılandırılmış ve bu eylemi teşvik edicidir. Hem kullanıcılarına daha fazla kontrol sunar hem de kullanıcılarından daha fazla katılım talep eder. Çevrim içi TV içeriği ile ilgilenen izleyiciler, tüketilebilir olduğu kadar navigasyonel ve düzenleyici bir oynatma listesini kullanır. Çevrimiçi platformları TV akışı için uygun portallar haline getiren kullanıcı ara yüzleri, temel ilke olarak bir programdan ziyade bir veri tabanının daha fazla benimsenmesini temsil eder. ${ }^{15}$ Bu gelişmelere bağlı şekilde, sıkça izleme davranışının değiştiğine dair söylemlerin ön plana çıktığı görülmektedir. Oturma odası TV için hala temel mekânı temsil etmesine karşın, tüketiciler giderek daha çok dizüstü bilgisayarlarda, tabletlerde ve akıllı telefonlarda video izlemeye başlamıştır. İster abonelikle içerik erişimi, isterse satın alınan içerik koleksiyonu için olsun, herhangi bir yer, herhangi bir zaman, herhangi bir cihaz mantığına dayalı dağıtım, video alanında gerekli bir giriş haline gelmiştir. Satın alınan içeriğin bulut tabanlı dağıtımı, tüketicilere çekici bir ürün sunar. Ancak herhangi bir yer, herhangi bir zaman, herhangi bir cihaz mantığına dayalı dağıtım vaadi iki önemli engelle karşı karşıyadır: platform parçalanması ve bant genişliği sınırlamaları. ${ }^{16}$

Akış, farklı endüstrilerin her birinde yeni ve etkili sektör oyuncularının temelini oluşturmaktadır. Bu açıdan düşünüldüğünde akış, yeni oyuncuların ve dolayısıyla potansiyel olarak yeni endüstriyel organizasyon biçimlerinin ortaya çıkmasına olanak sağlayan bir mekanizma görevi görür. Akış, birçok tüketicinin tükettiği medyanın yeniden kavramsallaştırıldığı ve tüketiciler ile etkileşime giren bir süreçtir. Sonuçta akış belirli bir medyayı aşan yeni medya tüketim davranış kalıpları için kültürel bir stenografi olarak görünür. Medya akışı çeşitli endüstriler arasında en azından yüzeysel bir ortaklık sağlar ve sayısallaştırma tarafından teşvik edilen yakınsamanın bir tür tezahürüdür. ${ }^{17}$

Video akışları, çevrim içi video, IPTV ya da internet TV gibi biçimlerde olmakla birlikte çevrim içi video internet üzerinde yer alan tüm video içeriğine işaret eden bir terim olarak kullanılır. Tüm filmler ve TV programları çeşitli siteler üzerinden satın

14 Sedat Özel, "Bir Yayın Platformu Olarak İnternette Çevrim İçi Videolar ve Kullanıcılarının Doyum Faktörleri”, Global Media Journal, 5 (2015), s.291-292.

15 Anne Gilbert, "Push, Pull, Rerun: Television Reruns and Streaming Media”, Television \& New Media, 20/7 (2019), s.687.

16 Gregory Gimpel, “The Future of Video Platforms: Key Questions Shaping the TV and Video Industry”, International Journal on Media Management, 17 (2015), s.36.

17 Herbert, Lotz ve Marshall, "Approaching Media”, s.351. 
alınabilir. Aynı zamanda geleneksel TV yayın akışında yayınlanmış ya da yayınlanıyor olan TV programları, TV kuruluşunun web sitesi üzerinden kolayca kullanılabilir. Ayrıca bu internet siteleri, internet için özel olarak üretilmiş gelecek bölümlerin tanıtım videoları, bir programdan silinmiş sahneleri ve sahne arkasında oyuncular ile röportaj videolarını da içerebilir. ${ }^{18}$

IPTV ve WEB (ya da internet) TV ise çevrimiçi videolardan biraz daha farklı bir yapısal dizayn ile hem birbirlerinden hem de çevrim içi videolardan ayrılırlar. TV kanallarına video akış teknolojisini kullanarak internet üzerinden ulaşılır ve gerçek zamanlı izlenilebilir. Bu Youtube gibi video sitelerinin mantığından farklıdır. Web TV uygulamaları ile çevrimiçi yayın akışı sağlanabilmektedir. Bu, geleneksel TV’nin sadece TV alıcı ekranında değil de internet tarayıcısında ulaşılabilir olması demektir. ${ }^{19}$

Radyo Televizyon Üst Kurulu’nun Kablolu Yayın Yönetmeliğinde yapılan tanıma göre IPTV yayını; radyo, TV yayınları ile talebe bağlı yayın hizmetlerinin geniş bant internet bağlantısı kullanılarak belli bir hizmet kalitesinde, özel yönetilen bir ağ üzerinden, DVB-IPTV standartlarında, internet protokolü (IP) uygulanarak, set üstü cihaz (set top box) veya bütünleşik TV alıcıları ile alınmasıdır. IP TV, geleneksel yayın hizmetlerinden farklı olarak, talebe göre içerik seçme, önceden yayınlanan bir programı izleme gibi olanaklar da sağlamaktadır. Yayın internet bağlantısından değil, aynı kablo altyapısından ancak farklı bir arabirimden aktarılır. IPTV' de yayın almak için set üstü cihaz (set top box) adı verilen cihazın bulunması gerekir.

Video akışları üzerinden TV yayıncılığında bir başka yayıncılık metodu ise OTT (Over The Top) hizmetleri olarak karşımıza çımaktadır. Talebe bağlı video hizmetlerinin hem IPTV hem de OTT hizmetlerinde var olması OTT'nin sıklıkla IPTV ile karıștırılmasına da neden olmaktadır. OTT (Over-The-Top), İnternet üzerinden yayınlanan görsel-işitsel içeriğin, içeriğin kontrolüne veya dağıtımına bir İnternet servis sağlayıcısının (İSS) katılımı olmadan kullanıcıya sunulmasını ifade eder. İSS, üçüncü bir taraftan gelen ve bir son kullanıının cihazına teslim edilen içeriğin izlenme biçimi, telif hakları ve/veya başka bir şekilde yeniden dağıtılmasından sorumlu değildir veya bunları kontrol edemez. İSS, OTT sürecinde sadece IP paketlerinin taşınmasında rol oynar. OTT, zaten alınan bir bağlantı hizmetinin üzerinden bize ulaştığından "over the top" olarak adlandırılır. Yani bir internet servis sağlayıcısına abone olarak web hizmetlerine ulaşan bir kullanıcı, OTT hizmetlerinden de yararlanabilir anlamındadır. OTT hizmetleri, içeriğin son kullanıcılara teslim edildiği altyapıyı kontrol eden veya sürdüren kuruluşla herhangi bir ticari veya teknoloji ilişkisi gerektirmez. ${ }^{20}$

18 Beverly A. Bondad-Brown, Ronald E. Rice ve Katy E. Pearce, "Influences on TV Viewing and Online Usershared Video Use: Demographics, Generations, Contextual Age, Media Use, Motivations, and Audience Activity”, Journal of Broadcasting \& Electronic Media, 56/4 (2012), s.472.

19 Cenk Demirkıran, "Geleneksel Televizyonun Sanal Modeli Olarak Web Tv ve Livestream Portalında TV Yönetimi”, Akdeniz Üniversitesi İletişim Fakültesi Dergisi, 14 (2010), s.76.

20 Chris Roberts ve Vince Muscarella, “Defining Over-The-Top (OTT) Digital Distribution”, The Entertainment Merchants Association. (erişim 06.05.2020). 
Tablo 1. IPTV ve OTT Arasindaki Temel Farklar ${ }^{21}$

\begin{tabular}{|l|l|l|}
\hline & IPTV & OTT \\
\hline Servis Sağlayıcı & $\begin{array}{l}\text { Yerel Çok Kanallı Video Yayın } \\
\text { Dağıtıcısı (AT\&T, DSMART vs) }\end{array}$ & $\begin{array}{l}\text { Yapım Stüdyosu, TV Kanalı ya da } \\
\text { 3. Parti Sağlayıcı }\end{array}$ \\
\hline Aktarım Ağı & $\begin{array}{l}\text { Yerel Telekom- Özel sahipli veya } \\
\text { kiralık ağ }\end{array}$ & Genel İnternet ve Yerel Telekom \\
\hline Alıcı & $\begin{array}{l}\text { Hizmet sağlayıcı tarafından } \\
\text { sağlanan Set üstü kutu }\end{array}$ & $\begin{array}{l}\text { Müşteri tarafından kullanılan } \\
\text { internet bağlantılı herhangi bir } \\
\text { ekran }\end{array}$ \\
\hline
\end{tabular}

Yüksek hızlı geniş bant hizmetlerinin kullanılabilirliğinin artmasının, video izlemek için OTT hizmetlerine ilgiyi de artırdığı düşünülür. Ancak Banerjee ve arkadaşlarına göre ${ }^{22}$ başka faktörler de OTT' nin büyümesi için eşit derecede önemlidir. Bunlardan ilki, çok işlevli veya "ağa bağlı" cihazların (bilgisayarlar, akıllı telefonlar, tabletler, oyun konsolları vb.) artık akışa ve indirmeye olanak sağlamasıdır. Bu cihazların tümü Internet özellikli ve gittikçe daha portatiftir. Aslında bunların çoğu, izleyiciyi sabit bir TV setine bağlanmaktan kurtaracak alternatif görüntüleme ekranlarıdır. İkinci olarak demografi, OTT davranışının önemli itici gücüdür. ABD’de yapılan araştırmalara göre sabit telefon aboneliklerini iptal etmede olduğu gibi, kablolu TV aboneliklerini iptal etmenin en büyük demografik etkeni, bağımsız veya yeni evlerde yaşayan genç tüketiciler ve geleneksel veya çok katmanlı TV hizmetine abone olma maliyetinden kaçınmak isteyen düşük gelirli tüketicilerdir. Bununla birlikte, önemli sayıda OTT kullanıcısı aslında geleneksel TV hizmetlerinden de yararlanmaktadır. $\mathrm{Bu}$ da genellikle birden fazla cihaz ve birden fazla abonelik alabilen yüksek gelirli tüketiciler grubu ile ilişkilidir. Onlar için, OTT’nin geleneksel canlı TV'ye eklenmesi "TV Her Yerde" yi gerçeğe dönüştürmektedir. ${ }^{23}$

Roberts ve Muscarella, ${ }^{24}$ OTT hizmetlerini üç iş modeli altında toplamaktadır: Canlı TV (Live TV), Elektronik Satış (Electronic Sell-Through), Talebe Bağlı Video. Canlı TV üzerine kurulu OTT hizmetleri, IPTV hizmetleri ile benzer şekilde içeriğin son kullanıcının görüntülemesi için internete bağlı bir cihaza canlı olarak aktarıldığı bir abonelik modeli hizmetidir. Ancak az önce de belirtildiği üzere kapalı bir yapı olan IPTV'den farklı olarak OTT hizmetlerinin temel esasını oluşturan HTTP (Hypertext Transfer Protocol) mantığına dayanır. Çok platformlu yayın ve Web 2.0'ın uygunluğu, TVde canlı yayın kavramını daha da değiştirmiştir. Çevirim içi uygulamalar, TV'deki canlı yayınlanan programların ömürlerini uzatmıştır. Öte yandan dijital uydu alıcıları, isteğe bağlı video servisleri ya da seyrettikçe öde sistemleri üzerinden her zaman ve hemen içeriğe erişebilir olmak isteyen izleyiciler için TVde canlı yayınların giderek önemsiz hale geldiği ileri sürülmektedir. Bununla birlikte daha fazla içerik kaydedildikçe ya da zaman kaydırmalı izleme ile daha önce olmadığı kadar

21 Roberts ve Muscarella, "Defining Over-The-Top".

22 Aniruddha Banerjee, James Alleman ve Paul Rappoport, "Video-Viewing Behavior in the Era of Connected Devices", Communications \& Strategies, 92 (2013), s.20.

23 Banerjee, Alleman ve Rappoport "Video-Viewing", s.20.

24 Roberts ve Muscarella, "Defining Over-The-Top". 
fazla TV izlenmektedir. Kitleler çeşitli cihazlarda aynı anda çoklu görev yaparken, her zamankinden daha fazla cihazda daha fazla içerik tüketilmektedir. ${ }^{25}$

Elektronik satış, bir tüketicinin dijital bir reprodüksiyonu satın aldığı veya ömür boyu lisansladığı modeldir. Bu lisanslı çoğaltma, tüketicinin internete bağlı aygıtına veya yerel sabit sürücüsüne indirilen bir dosya biçiminde veya son kullanıcıya talep üzerine akış için bir sanal depolama alanı veya bulut tabanlı hizmetteki içeriğe erişim yoluyla olabilir. Son olarak da talebe bağlı video hizmetleri (Video On Demand-VOD) iş modelini tamamlayan bir başka akış yöntemidir. Bunda izleyici istediği içeriğe internete bağlı bir cihaza indirerek ya da akış yoluyla ulaşabildiği ancak lisansına kalıcı olarak sahip olamadığı video içerikleri söz konusudur. ${ }^{26}$

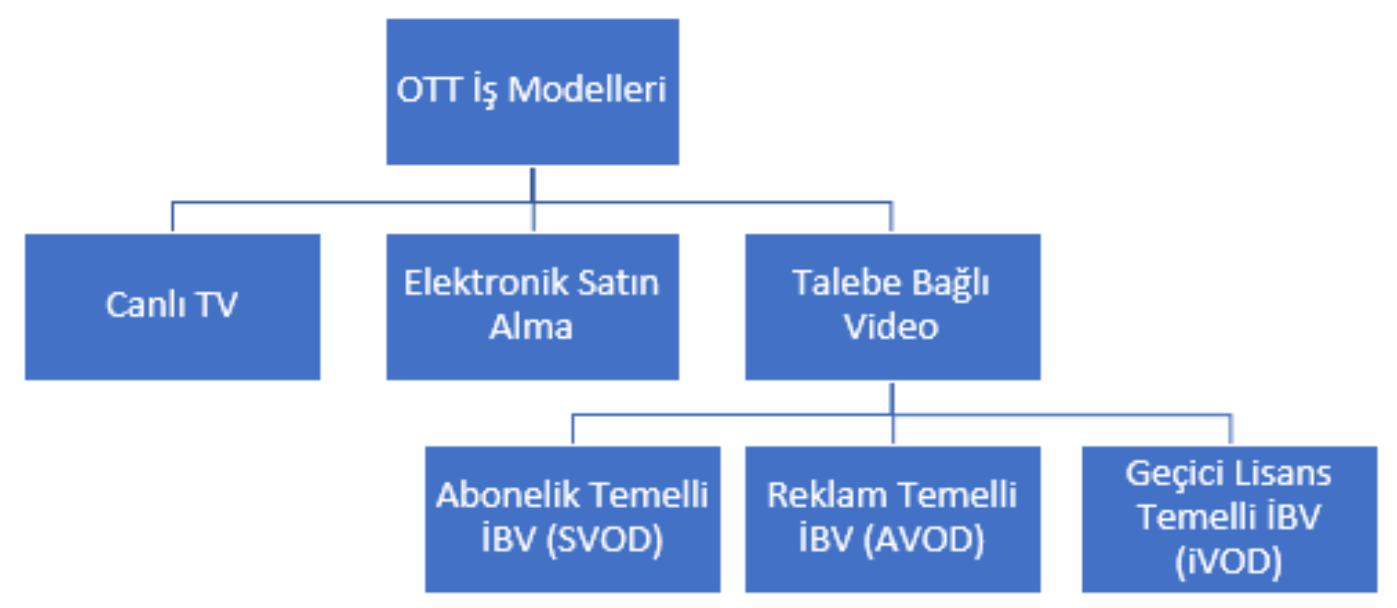

Şema 1. Roberts ve Muscarella’ya göre ${ }^{27}$ OTT İş Modelleri

Ancak talebe bağlı video hizmetlerinin farklı iş modelleri ile kullanıcıya sunulması nedeniyle sadece OTT ile sinırlı olmadığına dikkat edilmelidir. Bununla birlikte OTT ve talebe bağlı video hizmetleri sıklıkla birbirine karıştırılan kavramlar olarak karşımıza çıkar. Bunda dünya genelinde etkisini artıran OTT servislerinin etkisi büyüktür. Başta Netflix olmak üzere Amazon Prime ve ABD'de Hulu gibi OTT hizmetleri, talebe bağlı video hizmetlerine olan ilgiyi küresel ölçekte artırırken OTT ve talebe bağlı video hizmetlerinin de birbirinin yerine kullanılmasının önünü açmıştır.

\section{TV Yayıncılığında Bir İş Modeli Olarak Talebe Bağlı Video Hizmetleri}

Dijital yakınsamanın, kablosuz ağların ve geniş bant bağlantı olanaklarının TV’yi farklı ekranlara taşıdığı, bireyselleştirilebildiği gerçeği düşünüldüğünde, TV yayıncılığı, telekomünikasyon ve bilgisayar sektörlerindeki paydaşların çoklu ekran dünyasına uygun çözümler için çaba sarf etmesi bir gereklilik haline gelmiştir. Bu gereklilik, ekranlar ve sistemler arasında sorunsuz geçiş özelliğine sahip, tüm cihazların, ortamların uyumlu bir şekilde çalıştığ taya çıkarır. Öte yandan son yıllarda internet bağlantılı TV setleri, akıllı telefonlar

25 Sørensen, “The revival of live”, s.384.

26 Roberts ve Muscarella, "Defining Over-The-Top".

27 Roberts ve Muscarella, "Defining Over-The-Top". 
ve tabletlerin satışındaki artış, geniş bant alt yapının genişlemesi, talebe bağlı video hizmetlerinde penetrasyon oranlarının yükselmesi, küresel olarak çevrim içi TV’nin gelişiminde pozitif bir ivme yaratmıştır.

Seyircinin giderek daha fazla parçalandığı çok seçenekli medya ortamında, yayıncı kuruluşlar, çeşitli kitlelere hitap etmek için farklı iştirakler kullanarak izler kitlesini yeniden yaratmaya çalışmaktadır. Bu süreçte "katmanlama" olarak a bilinen bir uygulama ile hareket eden şirketler, aynı kurumsal semiyotik aile ve şemsiye içinde çok çeşitli niş içerikler üretmeyi hedefler. Aslında medya gruplarının daha geniş çıkarlarına hizmet etmek için niş TV izleyicileri kendi başlarına yeterli olmasa da yayıncıların bütçe ve rekabet güçlerini korumak adına birden fazla gelir akışı geliştirme gerekliliğinin bir çıktısı gibi görülür. Öte yandan Wayne’e göre ${ }^{28}$, daha küçük kitlelere, birden fazla dağıtım penceresindeki metinlerle etkileşime girdikleri, ticari ve lisanslı mallar satın alarak karlara katkıda bulundukları sürece hizmet verilebilir.

Gimpel $^{29}$, ev video pazarını oluşturan TME (telekomünikasyon, medya, eğlence) sektörünün farklı tasarım ve iş modellerini denediğine işaret eder. Çünkü bu dönemde standartlaşmış bir protokol olarak uygulanabilecek baskın bir piyasa tasarımında bahsetmek mümkün değildir. Örneğin YouTube’da kullanıcı tarafından oluşturulan içeriğin tüketimi ya da Apple iTunes tarafından indirilebilir video satışı gibi iş modelleri, ödemeli TV servisleri tarafından "Her yerde TV" (TV Everywhere) mottosu ile abonelere tanıtılan ayrıcalıklı video akış imkanları sektör geneline yayılan deneylerdir.

Talebe bağlı video, bir iş modeli olarak OTT hizmetlerinin çekirdek yapısını oluşturmaktadır. Medya şirketleri, bilgi ve iletişim teknolojilerindeki yeniliklerin getirdiği yeni iş modelleri ile karşı karşıyadır ve yeniden şekillenmektedir. Tüketiciler her yerde, her zaman, herhangi bir cihaz yaşam tarzını benimsemekte ve tüm servis sağlayıcılarından artan bir şekilde bu erişimi talep etmektedir. Çünkü tek bir tüketici teknolojisindeki gelişme başarılı olduğunda beraberinde diğer sunulan teknolojilerden de aynı beklenti geliştiğinden tüm firmalardan kullanımı kolay çözümler sunma talebi artmıştır. ${ }^{30}$

Aslında talebe bağlı video hizmetleri sayısal TV devriminden çok önce ortaya çıkmıştır. Bu kavram ilk olarak, Mart 1971'de Iowa City Press Citizen'de yayınlanan bir makalede, yayın zamanının yerine video kaset üzerinden TV programının izlenmesini anlatmak için kullanılmıştır. Planlanmış yayın zamanının dışında, zaman kaydırma ve izleme, bu gelişen kavramın öne çıkan özellikleridir. Teknoloji ilerledikçe yayın zamanlarının dışında TV program içeriğinin izlenmesi fikri önce DVD ardından internette korsan video ve nihayet çevrim içi TV yayın akışlarına doğru gelişmiştir. Netflix iş modeli de temelde bu teknolojik değişimi temsil eder. Çünkü DVD kiralama ve çevrim içi abonelik metodu ile içerik dağıtımını bir potada birleş-

28 Wayne, "Netflix, Amazon", s.726.

29 Gimpel, "The Future", s.27.

30 Gimpel, “The Future”, s.25. 
tirmiştir. $^{31}$

TV tüketicisinin deneyimi son yirmi yılda çok değişmiştir. Ancak bu değişim film ve müzikten farklı şekildedir. Öncelikle diğer iki endüstriden farklı olarak TV içeriği (2000'lerin başlarındaki DVD furyası dikkate alınmaz ise) irade ile satın alınamaz ve tüketilemez, bu nedenle de baskın TV izleme biçimi onlarca yıldır yayın planına odaklıdır. ${ }^{32}$ Daha açık bir ifadeyle geleneksel TV (ya da lineer TV), standart uzunluktaki programların belli bir yayın planının içinde izleyenler ile örtüşecek ve onların izleme eylemini teşvik edebilecek şekilde tasarımlanmış akışa bağlıdır. ${ }^{33}$ Bununla birlikte DVR gibi erken dijital teknolojiler, yayın planlamasına bağımlılığa karşı bir çözüm sunmuştur. 2012 yılı başına kadar talep üzerine video hizmetleri, abone tarafından finanse edilen ve görüntüleme başına ödeme yapılan filimler ile sınırlı kalmıştır. Ancak son dönem gelişmeler ile birlikte izleyicilerin kendilerine daha fazla seçenek sunan, yalnızca belirli bir anda açık olmanın aksine istenildiği zaman ulaşılabilen hali hazırda bir içerik kitaplığından seçim yapmalarına izin veren hizmetler ortaya çıkmıştır. ${ }^{34}$ Başka bir ifadeyle lineer olmayan TV, izleyici ile etkileşime girebilmekte ve izlenebilen ayrı dosyalar sunabilmektedir. Lineer olmayan TV, izleyicileri yayın akışının zamansal mantığından kurtarır ve internetin parçalanmış köprülü yapısı üzerinden çok sayıda görsel işitsel dosyayı izleyicinin dikkatine sunar. ${ }^{35}$

Ancak $\operatorname{Cox}^{36}$, TV'de yayın planlama mantığının hala daha var olduğuna da dikkat çeker. Ona göre dijital medya teknolojileri ve türleri, TV yayın planlama mantığı ile kolayca bütünleşir ve onu pekiştirir. Dijital medya platformlarını TV’ye alternatif olarak düşünen endüstriyel söylemlere rağmen araştırmacılar, TV’nin biçim ve işlevinin dijital medya platformları içindeki sentezine dikkat çeker. Kitle yayıncıllğı ile bireysel yayıncılık arasında, TV izleme ile video paylaşımı arasında ve programlar ile küçük parçacıklar arasında sıkı bir birbirine geçme bulunmaktadır. TV biçimi ve ticari yaklaşımlarını birleştiren böylesine bir iç içe geçme, Youtube’un TV gibi eski medya mekanizmaları ile aşamalı bir şekilde uyum sağlama becerisinden kaynaklanır. Böylece bağlanabilirliğin sürekli izleme ve katılım kapasitesine destek verdiği bir ekosistem gelişmiştir. Bu katılımın bir kısmı, dijital ortam biçimlerinin planlanmış akıştan işlenmiş kişiselleştirilmiş bir akış grubu sağlama kapasitesidir. Sayısal bağlanabilirlik ve TV’nin yakınsaması, endüstrinin ana akış ve çok kanallılığı sentezleme hayaline ulaşması adına bir adım gibi görülür. Bu çerçevede her izleyici için algoritma desteğinde özelleştirilebilen bir planlanmış akış ortaya konabilir. Bu yakınsama, kullanıcıların özelleştirilebilir yollar aracılığıyla TV’nin merkezi kitlesel çekiciliğini deneyimlemelerine olanak taniyabilir.

Bununla birlikte Netflix ve Spotfy gibi akış hizmetlerinin içerik katalogları, nispe-

31 Katie Ellis vd., “Access for Everyone? Australia’s 'Streaming Wars' and Consumers with Disabilities”, Continuum, 31/6 (2017), s.883.

32 Herbert, Lotz ve Marshall, “Approaching Media”, s.355.

33 Catherine Johnson, "Beyond Catch-up: VoD Interfaces, ITV Hub and the Repositioning of Television Online”, Critical Studies in Television, 12/2 (2017), s.134.

34 Herbert, Lotz ve Marshall, "Approaching Media”, s.355.

35 Johnson, "Beyond Catch-up", s.134.

36 Cox, "Programming - Flow”, s.440. 
ten istikrarlı seçim özgürlüğüne delil gibi görünse de birçok platformun, hala Williams’ın akış kavramı ile ilişkilendirilebilecek şekilde, kullanıcılarının içeriği keşfetme şekli ve zamanlamasını yönlendirmeye çalıştığ düşünülebilir. İnsanlar, kişiselleştirilmiş içerik akışlarında gezinmek için ara yüzler, uygulamalar, ekranlar ve sosyal medya aracılığıyla algoritmalar, yapay zeka (AI) ve botlarla etkileşime girer. Diğer bir deyişle, doğrusal bir TV kanalından farklı olarak, çevrimiçi platformlar izleyicileri ikili bir tüketim seçeneğiyle sınırlamaz. Daha ziyade bu platformlar, dinamik olarak açılan, kişiselleştirilmiş bir seçim mimarisi sağlar. ${ }^{37}$

Yine de internette video akışlarının TV deneyimine kapsamlı bir değişiklik getirdiği sıkça dile getirilir. Yayıncılık anlayışı takvim tanımlı programlamadan kurtulmuş ve "Abonelik" TV sektörü için birincil finansman mekanizması olarak önemini artırmıştır. Bu, reklamlar tarafından yapılandırılmamış bir izleme deneyimine izin vermektedir ve reklam finansörlüğünden oldukça farklı bir TV içeriği oluşmasına neden olmuştur. Ayrıca bu hizmetler, izleyicilerin DVD setleri ile deneyimlediği haftalık bekleme zorunluluğunu aşma yeteneğini pekiştirirken, bağlı olarak tıkınırcasına izleme (binge) davranışını da normalleştirmiştir. ${ }^{38}$

OTT hizmetleri ve talebe bağlı video için artan tüketici tercihi, geleneksel TV programları, derecelendirmeler, reklamlar ve platform abonelikleri (uydu, kablo vs.) üzerinde yıkıcı bir etkiye sahiptir. ${ }^{39}$ Netflix ve Youtube diğer web tabanlı akış servisleri ile birlikte, sadece TV’lerden ulaşılabilen içeriği değil aynı zamanda kendi orijinal içeriğini de kullanıcılara sunarak medyanın üretim-dağıtım tabiatını değiştirmektedir. Bu nedenle, bu Web tabanlı servisler kendilerini geleneksel TV içerik sağlayıcılarıyla doğrudan rekabet edebilecek şekilde konumlandırmaktadır. Bu yeni teknolojilerin ardından tüketiciler, dijital yaşam tarzlarıyla uyumluluğu ve izleme seçeneklerini geliştirmesi nedeniyle geleneksel metotlarla yayın ulaştıran ücretli hizmetleri iptal etme yönünde hareket etmektedir.

Geleneksel kablolu TV veya uydu üzerinden alınan ücretli TV izleme aboneliklerini iptal ettiren tüketiciler literatürde "kablo kesici" olarak adlandırılır. Aslında Kablolu TV’lerin çoğu uydu üzerinden iletilmesine ve çoğu kablo kesicinin geniş bant internet erişimi için Telekom sağlayıcıları ile bağlantılarını korumasına karşın "kablo kesme" terimi geleneksel kablolu hizmetlere erişim ile tüketici arasındaki bağın kopmasına mecazi bir gönderme olarak kullanılır. Bu süreç geniş bant internet bağlantıları ve Netflix, Hulu, Amazon Prime gibi WEB akış servislerine abonelikler ile hız kazanmıştır. Bu kitle TV'den elde ettiği eğlence içeriği için web tabanlı yayınlara güvenir. ${ }^{40}$

Öte yandan geleneksel yayıncılar için talebe bağlı video hizmeti, izleyicilere kaçırdıkları programları izleme fırsatı sağlayan bir yakalama hizmeti mantığı etrafında şekillenir. Geleneksel yayıncının bu yaklaşımı doğal olarak onu doğrudan aslında

37 McKelvey ve Hunt, "Discoverability: Toward", s.2.

38 Herbert, Lotz ve Marshall, “Approaching media”, s.355.

39 Sidneyeve Matrix, "The Netflix Effect: Teens, Binge Watching, and On-Demand Digital Media Trends", Jeunesse: Young People, Texts, Cultures, 6/1 (2014), s.120.

40 Alec Tefertiller, "Media Substitution in Cable Cord-Cutting: The Adoption of Web-Streaming Television", Journal of Broadcasting \& Electronic Media, 62 (2018), s.390-391. 
talebe bağlı videonun bir tamamlayıcı hizmet olduğu fikrine taşır ve geleneksel yayıncının ana rolü ile örtüşür. Bu tür hizmetler, Netflix ve Apple gibi firmaların talebe bağlı video anlayışından farklıdır. ${ }^{41}$ Normalde, izleyiciler platformlara ve bölgelere göre bölümlere ayrılır ve TV içeriği bir dizi ardışık pencere üzerinden yerel ve uluslararası pazarlarda sunulur. İçeriğin farklı izler kitle kümelerine nasıl sunulacağını tanımlayan zamanlama ve diğer koşullar, ürüne talep oluşturmak için yakından yönetilir. Bununla birlikte sayısallaşma, internetin büyümesi, içerik oluşturucuların kitleleri kümelere ayırma ve gelirleri en üst düzeye çıkarmalarına izin veren geleneksel stratejilerini uygulama yeteneklerini bozmuştur. ${ }^{42}$

1990'ların başında program tedarikçileri için mevcut olan ana dağıtım pencereleri tipik olarak birincil ve ikincil ulusal yayın kanalları ile ulusalar arası pazarlardı. İlk iletim ve ilk pencere hakları genellikle tüm üretim maliyetlerini karşılayacak şekilde yurt içi bir işletmeye verilir. Bu ilk pencerenin ardından içerik, kablolu platformlar gibi bir dizi uluslararası ve ikincil yerel pencereye doğru genişler. Bununla birlikte 1990'ların başından bu yana TV'de içeriğin dağıtım biçimlerinde ve izleyicilerin içeriğe erişim ve tüketim şekillerindeki değişimler pencereleri de çeşitli şekilde etkilemiştir. 2000'lerin ilk çeyreği geçildiğinde ise pencerelerin sayıca genişlemiş olduğuna vurgu yapılır. Endemol Shine’in eski CEO’su Payne, ilk büyük değişikliğin dijital karasal yayınların ortaya çıkışıyla başladığına dikkat çeker. Birdenbire daha fazla satış noktası ortaya çıkmıştır. Hem büyük hem de küçük (niş) pazarlar vardır. Diğer yandan içeriğin kopyalarının dijital olarak satın alınabilmesi ya da kiralanabilmesi mümkün hale gelmiştir ve günümüzde OTT platformları, bu değişime yeni pencereler eklemiştir. ${ }^{43}$

Dijital teknoloji sadece TV içeriği için yeni pencereler eklemekle kalmadı, aynı zamanda içeriğin izleyicilere sunulabileceği pencerelerin doğasını da değiştirdi. Örneğin dijital olarak sunulan içeriğin izinsiz kopyalanıp dağıtılabilmesi, bunun kontrolünün zorluğu, pazarın farklı segmentlerine içeriğin aktarılmasını hızlandırmıştır. Öte yandan çevrim içi platformların yayıncılık pazarına eklenmesi, içeriğe genişletilmiş erişim sağlayan ve çok yönlü bir alan kaplayan bir dizi yeni talebe bağlı video hizmeti sunmuştur. $\mathrm{Bu}$, haliyle pencereleme sürecinin daha karmaşı bir hal almasına neden olur. İnternet öncesi bir dönemde, kitleleri ayrı kümelere ayırmak ve mevcut pencerelerdeki içeriğin yayınını kontrol etmek nispeten basitti. Şimdi ise OTT hizmetleri sayesinde dağıtım için bazı pencereler çok yönlü olanaklar içerir ve birçoğu genişletilmiş erişim sağlar. Pencereler daha geçirgen ve üst üste oldukça içerik üreticileri, lider içeriklerin pencerelere özenle sürülmesini sağlayan stratejilerinin bozulması sorunu ile karşı karşıya kalmıştır. Bu yüzden farklı pencerelerin değerini tartma ve içeriğin getiriyi en üst düzeyde sağlayacak şekilde sürülmesini organize etmek daha karmaşık bir hal almıştır. ${ }^{44}$

41 Johnson, "Beyond Catch-up", s.124.

42 Gillian Doyle, "Digitization and Changing Windowing Strategies in the Television Industry: Negotiating New Windows on the World", Television \& New Media, $17 / 7$ (2016), s.630.

43 Doyle, "Digitization and", s.632-633.

44 Doyle, "Digitization and", s.634-635. 


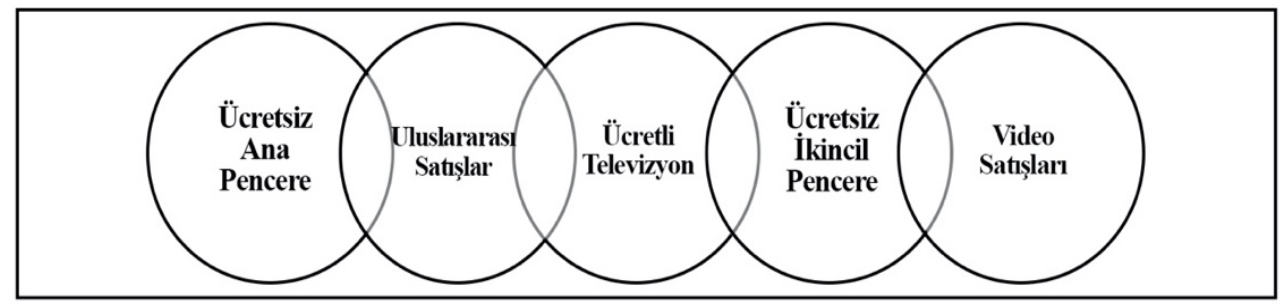

1992 'de televizyon içeriği pencerelemesi.

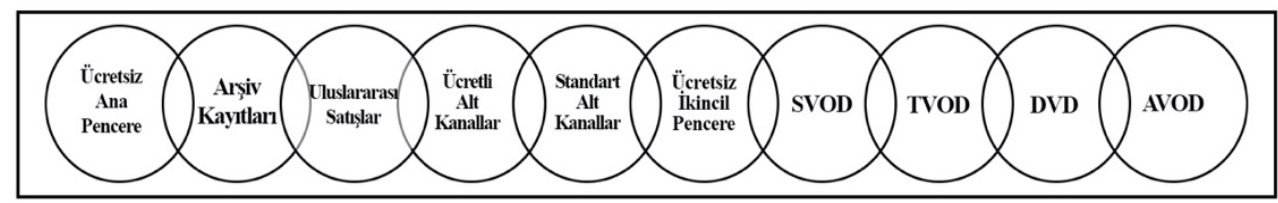

2015 'te televizyon içeriği pencerelemesi.

Not. SVOD: Abonelik Temelli Talebe Bağı Video Hizmetleri; TVOD: Öde İzle Temelli Talebe Bağlı Video Hizmetleri AVOD: Reklam Temelli Talebe Bağl Video Hizmetleri

\section{Şema 2. TV Pencereleme Stratejileri ${ }^{45}$}

Tipik bir talebe bağlı video hizmeti, kullanıcıların geniş bir video koleksiyonundan herhangi birini istedikleri zaman izlemelerini sağlar. Talebe bağlı video, IPTV'den kablolu TV aboneliğine farklı iletim biçimlerinde var olan bir hizmettir. Bu şekilde düşünüldüğünde OTT, aslında talebe bağlı video hizmetleri kategorisinde bir alt küme olarak düşünülebilir.

OTT uygulamaları ve servislerinde sunulan talebe bağlı video hizmetleri reklam temelli (AVOD), abonelik temelli (SVOD), öde izle temelli (TVOD) olarak ayrılır. Youtube, Vimeo, Dailymotion gibi servisler öncelikle iş modelini reklam temelli olarak kurmuştur. Netflix, Amazon Prime, Hulu gibi OTT servisleri ise Abonelik temelli bir iş modelini takip eder. Aboneler her ay için belirlenen hizmet bedelini ödeyerek içeriklere ulaşabilir. Öde-İzle temelli (TVOD) hizmet modelinde ise normalde hizmete kaydolmak / kullanıcı profili oluşturmak için herhangi bir ücret talep edilmez. Bunun yerine, izlenen içeriğe göre bir tutar ödenir. Ekseriyetle film alımları bu sistem üzerinden sunulur. Ancak dizi ve özellikle spor etkinlikleri de öde-izle iş modeli üzerinden sunulabilmektedir. ITunes küresel çaptaki en güçlü öde-izle servisidir.

Yayıncılığa yaklaşık yetmiş yıldır hâkim olan örgütsel biçim, dijital TV’nin piyasaya sürülmesi ile birlikte artan izleyici kontrolü ve özgürlük vaatlerinin ardından sorgulanmaya başlanmıştır. ${ }^{46}$ Seyircilerin TV içeriğini tükettikleri medya kuruluşlarının çoğalması ışığında Curtin, özellikle 2007 sonrası TV’yi matris medya olarak görmemiz gerektiğini savunur. Bu karmaşık medya ortamında matris TV, etkileşimli alışverişler, çoklu verimlilik siteleri ile çeşitli yorum ve kullanım modları üzerinden karakterize edilir. Ona göre Netflix, Vimeo veya Youtube gibi servisler

45 Doyle, "Digitization and".

46 Moe, “Television, Digitalisation”, s.775. 
film, TV, DVD ve çevrimiçi video platformları arasındaki ayrımın bozulmasına mükemmel bir örnektir. Muhtemelen TVIV, izleme modellerinin, markalama strateji-

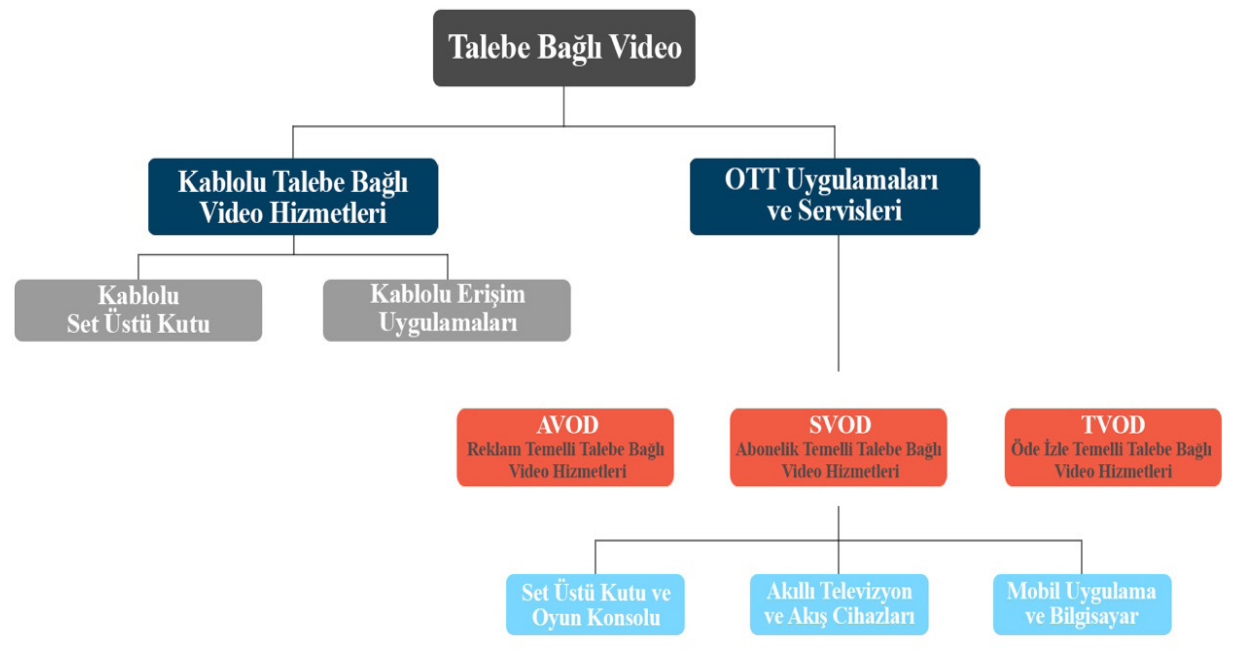

Şema 3. Talebe Bağhl Video Hizmet Biçimleri ${ }^{47}$

lerinin, endüstriyel yapıların, farklı medya formlarının birbiriyle etkileşime girme biçimini ve içeriğin sadece TV alıcısı ile sınırlı kalmadığı çeşitli yolları içeren bir dönemdir. ${ }^{48}$ Geçmişte, güçlü oyuncular endüstri değer zincirini sıkı bir şekilde kontrol ederken bugün artan bir şekilde ittifaklar kurulmaktadır. Bu ittifakları oluşturan ortaklar içerik ve hizmetlerin katma değerini artırıcı özelliklere katkı sağlarken kendi temel değerlendirme yetkinliklerine de konsantre olmaktadır. Amaç değer sunumunun en üst düzeye çıkması, maliyetlerin en aza indirilmesidir ve bu değer ağları birbiriyle ilişkili dijital platformlar üzerine kurulmuş karmaşık ekosistemler olarak şekillenmektedir. ${ }^{49}$

Kullanıcı deneyimindeki en derin değişiklik yeni oyuncular tarafından başlatılan inovasyondan kaynaklanır. Başlangıçta teknolojideki ilerlemeye bağlı olarak medyayı tüketme biçimlerinde yenilik deneyleri tüketiciler tarafından benimsenmiş ve tercih edilmiş dolayısıyla sektörün yerleşik şirketleri bu yeni tüketici uygulamalarını desteklemeye zorlanmıştır. Hem film hem de TV'de en yaygın kullanılan akış hizmetlerini destekleyen iş uygulamaları, geliri belirli başlıklara veya kullanım sayısına bağlamak yerine belirli bir süre IP kanallarına sabit bir ücret karşllığ satarak pencereleme yöntemini genişletmiştir. Ancak TV'deki ticari pratikler reklam verenlerin fonladığ 1 ücretsiz izleme deneyiminden doğrudan ödeme gerektiren ama daha fazla kontrol ve izleme rahatlığı sağlayan yeni modellere doğru kaymaktadır. ${ }^{50}$ Dijitalleşme ile TV ara yüzleri, kişiselleştirilmiş izleme modelleri sağlamış ve TV deneyimi ustaca yeniden biçimlendirilmiştir. ${ }^{51}$

47 "Unterstanding the Difference between VOD and OTT", son güncelleme 17 Mart, 2019, https://clipbucket. com/2019/03/07/understanding-the-terms-svod-avod-tvod-and-the-difference-between-vod-and-ott/

48 Curtin 2009'dan aktaran Mareike Jenner, "Is This TVIV? On Netflix, TVIII and Binge-watching", New Media \& Society, 18/2 (2016), s.260.

49 Gimpel, "The Future", s.27.

50 Herbert, Lotz ve Marshall, "Approaching Media", s.362.

51 Daniel Chamberlain, “Television Interfaces", Journal of Popular Film and Television, 38/2 (2010), s.85. 


\section{Yeni Bir İzleme Deneyimi: Netflix ve Pazarlama Stratejilerine Bir Bakış}

Netflix, Web tarayıcıları veya çeşitli donanım türlerinde çalışan yazılım uygulamaları aracılığıyla sunduğu içeriğe, isteğe bağlı erişim sağlayan bir video akış hizmetidir. Günümüzde bir video içerik kütüphanesine erişim izni veren aylık abonelikler satan şirket, ilk olarak 1998 yılında posta yoluyla DVD aboneliği satmaya başlamıştır. 2017 y1lında DVD aboneliği Netflix'in 110 milyon abonesinin 3.3 milyonunu oluştururken şirketin öncelikli odak noktası, internet üzerinden anında erişilebilen dijital medya içeriği kütüphanesi için aylık abonelikler satmak olmuştur. ${ }^{52}$ Aboneler, katalogdan seçtikleri herhangi bir videoyu TV, dizüstü bilgisayar, telefon ve tabletler dahil Netflix uygulaması ile internete bağlı herhangi bir cihazdan izleyebilir.

Birçok yönden abonelik temelli talebe bağlı video hizmeti (SVOD), bir tür sanal video mağazasına benzer. Burada, raflardaki video kutularının yerini bir menü ekranındaki küçük resimler almıştır. Bir manada Netflix, SVOD üzerinden bir dizi mevcut alışveriş, kiralama ve tüketim uygulamasını alıp bunları birleştirmiş ve geliştirmektedir. $\mathrm{Bu}$ hizmetler bir kullanıcının internet bağlantısı olan bir cihaz üzerinden herhangi bir filmi tüketmesi anlamına geldiği için eskiden kablolu kanallar ve ödemeli sistemlerden sunulan öde izle hizmetlerindeki rahatlı̆̆ı genişletir. SVOD filmlere erişmeyi ve tüketmeyi kolaylaştırmıştır ve görünüşte daha bol ve sonuç olarak kişisel zevklere daha fazla hitap etmekle birlikte daha ucuz görünmektedir. ${ }^{53}$

Talebe bağlı video hizmetlerinin belki de küresel çapta dikkat çekici bir hale dönüşmesinde güçlü bir katalizör olan Netflix abone sayısı Nisan-2020 itibariyle tüm dünya genelinde 180 milyon civarındadır. Bu elbette dünya nüfusu ile karşılaştırıldığında yüksek bir rakam olarak görülemez. Öte yandan dünyanın hala büyük bir kısmında geniş bant ağ alt yapısı ve bağlı teknolojiler de bulunmamaktadır. Ancak OECD $2018^{54}$ verilerine bakıldığında dünya genelinde 410 milyona yakın sabit geniş bant aboneliği ile 1,5 milyara yakın mobil geniş bant aboneliği vardır. Bununla birlikte Netflix’in işaret ettiği değişim teknolojinin sonuçları ile ilişkili gibi görünse de markalaşma ve yayın planlama stratejileri, zamanlamadan bağımsız bir şekilde izleyici davranışının doğru analizi ve bir programın başarısının ölçümünde yerleşik TV kavramlarının ötesinde yaklaşımı ile ilişkilidir. Jenner'a göre ${ }^{55}$, TV-IV ortamında TV’nin mevcut bilinen kavramları ortadan kalkmaz ancak bu kavramlar önemli ölçüde genişletilir ve bu matriste bir dizi başka medya formu ve söylemi ile ilişkilenir

Abonelik için ekran verimliliğine ve video çözünürlüğüne dayalı üç akış planı sunan şirket, her ay mevcut üyelerini korumanın yanında yeni abonelikler kazanmaya çalışır. Netflix'in abone çekmek ve elde tutmak için başlıca stratejilerinden biri, yalnızca Netflix'te bulunan orijinal içerik üretiminin artmasıdır. Tıpkı Williams’ın dikkat çektiği kitle TV’lerinde yayın planlama stratejisinin dayandığı bir akşam akışı boyunca izleyicilerin dikkatini korumak ve yakalamaya yönelik ekonomik güdülerde

52 Cox, "Programming - Flow", s.445.

53 Herbert, Lotz ve Marshall, "Approaching Media”, s.354.

54 “OECD Stat”, erişim 5 Ekim, 2020, https://stats.oecd.org/.

55 Jenner, “Is This TVIV?", s.270. 
olduğu gibi Netflix'in de her ay abonelerini elinde tutması gerekir. Diğer şirketlerden lisanslı içerik sunmasına rağmen Netflix, orijinal içeriğini yeni ve mevcut izleyicileri yakalamak için birincil araç olarak kullanmaktadır. ${ }^{56}$ Bunun şirket tarihinin en yüksek çeyreği olan 2017'inin son çeyreğindeki abone artışının temel nedeni olduğu da ifade edilmiştir.

Aslında abonelik temelli talebe bağlı video hizmetlerinde (SVOD) markalaşma ve pazar stratejilerinin ayrılmaz bir parçası olan orijinal içeriğe yatırım, farklı üst düzey içerikler konusunda uzmanlaşmış içerik tedarikçileri için mükemmel fırsatlar yaratmıştır. Bununla birlikte SVOD hizmetlerindeki büyümenin, üreticiler ve dağıtıcılar arasında içerikten elde edilen getirileri en üst düzeye çıkarma noktasında sağlayacağı yararlara dair farklı görüşler vardır. Hatta dijital ve çevrim içi dağıtım pencerelerindeki büyümenin tüketim davranışlarına uzun vadede etkisini tahmin etmede yaşanan zorluk rahatsızlık yaratmaktadır. Bununla birlikte SVOD hizmet sağlayıcılarının sahip oldukları ayrıntılı izleyici verilerini içerik üreticileri ile paylaşmada isteksizliği, belirsizliği de güçlendirmektedir. Tüm bunlara rağmen SVOD hizmet sunucularının içeriği sürekli güncel ve ilgi çekici tutma çabası, içerik üreticileri için iyi bir gelir kapısı yaratmış durumdadır. ${ }^{57}$

Bir kütüphane oluşturma ve sürdürme işinin izlenebileceği ve pazarlanabileceği birçok farklı strateji vardır. Bununla birlikte tek başına orijinal içerik stratejisi her ne kadar güçlü ve yararlı gibi görünse de uygulamadaki oranlar bunun çok da yeterli olamayacağına işaret etmektedir. Örneğin 2016 Mart ayında, Netflix'de sunulan 1200 şovdan sadece 98'i (yaklaşık \%8) i orijinal marka üretimidir. Netflix'in kütüphanesindeki TV içeriğinin büyük çoğunluğu, geleneksel TV marka uygulamalarına uygun bir şekilde düzenlenen sistem tarafından üretilmiş ve ilk dağıtımı bu mantığa göre yapılmıştır. ${ }^{58}$

Yine de SVOD hizmetlerinin içerik stratejileri, rakip yayıncılar için ve dolayısıyla ellerinde tuttukları takipçi kitlesi için potansiyel bir tehdit oluşturur. Büyük abone seviyelerine ulaşan SVOD hizmetleri, dikkat çekebilecek büyüklükte içeriklere yatırım yapmak için açık ve zorlayıcı gerekçelere sahiptir ve bunu gerçekleştirir. Ancak, giderlerini reklam gelirlerinden karşılayan TV istasyonlarının, SVOD hizmetleri ile kitlesi bölünürken, dikkat çekebilecek maliyetli projeler içinde bulunması ekonomik olarak mantıklı görünmemektedir. Buna rağmen pazardaki rekabet büyük maliyetli projelerin desteklenmesini ve TV'de içerik üretimi için benzeri görülmemiş derecede yüksek üretim bütçelerini ortaya çıkarmıştır. Bu noktada uluslararası dağıtım pencereleri artık bu maliyetlerin telafisi için ortaya konan stratejilerin kritik bir bileşenini oluş̧urmaktadır. ${ }^{59}$

Bununla birlikte, Netflix'in orijinal içerik üretimi ve yayın planlaması genellikle özel bir metadan daha fazlası; kültürel deneyime özel bir giriş kapısı olarak görülür. ${ }^{60}$

56 Cox, "Programming - Flow"; Jenner, "Is This TVIV?”.

57 Doyle, "Digitization and", s.636.

58 Wayne, "Netflix, Amazon", s.730.

59 Doyle, "Digitization and".

60 Cox, "Programming - Flow", s.445. 
Şirketin hizmet biçimi, kişiselleştirilmiş izleme modelleri ve TV akışının bireysel planlanması üzerine kuruludur. Bireysel tercihlere yapılan bu ağır vurgu post modern kapitalizmin savunusu ile de örtüşür. Bu nedenle, üretim, dağıtım ve sergi arasındaki çizgilerin bulanıklaşması, yalnızca tüketici alışkanlıklarını ve kimlik inşasını birbirine bağlayan tüketicilere yol açan bir pazarın mantıklı bir sonucu olabilir. Başka bir deyişle, Netflix'in kişiye özel ürünü yalnızca bu sürecin de kişiselleştirildiği bir dağıtım sisteminde çalışabilir. ${ }^{61}$ Öte yandan Cox'a göre ${ }^{62}$, Netflix orijinallerinden Stranger Things karakterlerinin, görüntülerinin ve diğer motiflerin geniş dolaşımında olduğu gibi artan şekilde kültürel metinlerin, kalıpların ve deneyimlerin bir araya geldiği özel bir kanal algısı kültürel uygulanabilirlik pratikleri ile birleşerek yayın ve nakit akışının korunmasına yardımcı olur.

Genellikle SVOD hizmetleri teknolojik ilerleme ve kitle katılımının yeni biçimleri ile ilişkili şekilde "kaliteli TV" söylemini kullanır. Bu açıdan Netflix teknolojik ve kültürel açıdan en ileri teknolojiye sahip daha çekici bir TV akışına vurgu yapar. SVOD hizmetleri genellikle tıkınırcasına izlemeyi (binge watching) bir kitle davranış modu olarak vurgulayarak geleneksel TV'nin canlı yayın ve doğrusal akışı planlamasına karşı ön plana çıkarır. ${ }^{63}$ Netflix, düzenli olarak planlanan haftada bir gün aynı saatte bir yeni bölüm yayınlamak yerine şovlarının tüm sezonunu bir kerede yayınlamayı seçerek radikal bir adım atmıştır. Geleneksel TV’de uzun süredir yaygın olan "programlı izleme" den "binge wathcing” olarak adlandırılan art arda birkaç bölümü izleme için abonelere sağlanan bu imkân, şirketin izleme verilerini analizinden ortaya çıkmıştır. Çünkü bu veriler müşterilerin bir seferde bir yerine birkaç bölümü izleme eğiliminde olduğunu göstermiştir. ${ }^{64}$ Netflix 2013 yılında Arrested Development dizisinin yeni sezon bölümlerinin tamamını aynı gün yayınladığında izleyicilerin \%10'unun tüm sezonu 24 saat içinde izledikleri tespit edilmiştir. Genelde çalışmalar tek bir izleme oturumundaki izleme sayllarına odaklanmakla birlikte Netfix'in verilerine göre bir TV dizisi için izleyicilerin \%25'inin 13 bölümü sezonun yayına verildiği iki gün içinde bitirdiği, \%50'sinin ise bir hafta içinde sezonu tamamladığ 1 bilinmektedir. ${ }^{65} \mathrm{Bu}$ yayın planlamasının ise talebe bağlı video hizmetlerine ilgiyi tetikleyen ana etmen olduğu ileri sürülmektedir. ${ }^{66}$

İzleyiciler, tipik bir televizyon yayın akışında olduğu üzere her hafta dizinin bir bölümünü tüketmektense, tek bir dizinin birkaç bölümünü arka arkaya izleme eğilimindedir. Schweidel ve Moe ${ }^{67}$ bir oturuşta bir TV dizisinin üç veya daha fazla bölümünü izlemenin "binge watching” olarak tanımlandığını söylemiştir. Keza Netflix adına Haris İnteractive tarafindan yapılan bir ankette, seri izleme (binge watching) arka arkaya 2-3 bölüm izlemek olarak tanımlanmıştır. Aşırı izlemenin iki ortak unsuru vardır. Birincisi, tek bir oturumda veya kısa bir süre içinde meydana gelen birden

61 Jenner, "IsThis TVIV?", 267.

62 Cox, "Programming - Flow", s.446.

63 Wayne, "Netflix, Amazon", s.730.

64 Blake Hallinan ve Ted Striphas, "Recommended for You: The Netflix Prize and the Production of Algorithmic Culture”, New Media \& Society, 18/1 (2016), s.129.

65 David A. Schweidel ve Wendy W. Moe, "Binge Watching and Advertising”, Journal of Marketing, 80/5 (2016).

66 Matrix, “The Netflix Effect”, s.119.

67 Schweidel ve Moe, "Binge Watching". 
fazla oturumda ortaya çıkabilecek ağır bir tüketim oranı vardır. İkincisi, aşırı izlemeyi maraton izlemeden ayıran önemli bir özellik, aşırı izlemenin aynı serinin birden çok bölümünü tüketmeyi temsil etmesidir. Bu iki özellik, Oxford Sözlüklerinin 2014 yılında çevrimiçi sürümüne eklediği "tıkınırcasına izleme" tanımı ile tutarlıdır. Oxford Sözlüklerine göre tıkınırcasına izleme “Tipik olarak DVD’ler veya dijital akış yoluyla (art arda televizyon programı) birden fazla bölümü hızlı bir şekilde izlemek" anlamina gelmektedir. ${ }^{68}$

Tikınırcasına izleme kavramı, yayınlamış programların serilerini içeren DVD setlerinin piyasaya sürülmesi ve izleyicinin bu kutu setlerine ilgisiyle ortaya çımıştır. ${ }^{69}$ Ancak bugün bir pazarlama stratejisi olarak tıkınırcasına izleme bir SVOD hizmetinde dikkat çeken önemli bir faktördür. ${ }^{70}$ Aslında yıllar boyunca teknolojideki gelişmelere bağlı olarak TV izleme şeklimiz neredeyse her zaman değişmiştir. Uzaktan kumandalar sörf yapmayı kolaylaştırırken kişisel video kaydediciler insanları gerçek zamanlı izlemeden uzaklaştırdı. "Maraton görüntüleme" sonrasında "tıkınırcasına izleme", giderek popülerliğini artırmıştır. Son dijital devrim ve geniş bant iletişim, TV izleme alışkanlıklarımızı önemli ölçüde etkilerken bir TV içeriği herhangi bir dijital ortamda sunulmaktadır. Buna bağlı şekilde tıkınırcasına seyretme artık çok sayıda cihaz üzerinden gerçekleştirilebilmektedir. ${ }^{71}$

Aşırı izlemenin önemli bir faktörü, planlanmış yayın akışına bağlı TV ile bağlantısının kesilmiş olmasıdır. ${ }^{72}$ Daha açık bir ifadeyle tıkınırcasına izleme terimi geleneksel TV'den farklı olan video akışları için geçerlidir. Sonuçta terim bir TV akışı içindeki ardışı içeriğin saatlerce izlenmesi ile ilişkili değildir. Daha ötesinde bir dizinin tüm bir sezonu ya da sezonlarını izlemek ile ilgilidir. İzlenen bölüm sayısının fazlalığını belirlemek adına kıstas, geleneksel TV akışındaki programlama mantığı karşılaştırması ile gelişir. Bu açıdan düşünüldüğünde normal akışta haftada bir program içeriği yayınlanır ve tükettirilir. Bu noktada bir günde tüm sezonu izlemek aşırı görülür. Aslında norm ve buna karşı olan fazlalığın ne olduğunu saptamak zor görünebilir ama söz konusu olan, planlanmış rasyonel akışa sahip TV’nin izleyiciye teklif ettiği şeyden farklı bir izleme eylemidir. Bu izleme şekli, çeşitli programları içeren bir TV akışını kesintisiz olarak izlemekten farklı bir durumdur. Daha ziyade bir metin ile yoğun ya da aşırı yakın ilişskiyi ima eder. ${ }^{73}$

Sung ve arkadaşları, ${ }^{74}$ tıkınırcasına izleme davranışının sonuçta medya kullanım motivasyonları ile örtüşmesi gerektiğine dikkat çeker. Bu açıdan bakıldığında olumsuz duygulardan kaçma, duygu durumunu düzenleme, zaman doldurmak gibi motivasyonlar tıkınırcasına izleme için geçerlidir. Diğer yandan kaçış ya da kendini

68 Schweidel ve Moe, "Binge Watching".

69Mareike Jenner, "Binge-watching: Video-on-demand, Quality TV and Mainstreaming Fandom", International Journal of Cultural Studies, 20/3 (2017), s.307.

70 Wayne, "Netflix, Amazon", s.726.

71 Yoon Hi Sung, Eun Yeon Kang ve Wei-Na Lee, "Why Do We Indulge? Exploring Motivations for Binge Watching", Journal of Broadcasting \& Electronic Media, 62 (2018).

72 Jenner, "Is This TVIV?", s.265.

73 Jenner, "Binge-watching", s.306-307.

74 Sung, Kang ve Lee, "Why Do We Indulge?". 
ödüllendirme gibi motivasyonların da bu eylemde etkin olduğu dile getirilir. Sung ve arkadaşları ${ }^{75}$ akran etkisinin de aşırı izlemede aktif bir motivasyon olduğuna vurgu yaparken Conlin ve arkadaşları ${ }^{76}$, bir şeyleri kaçırma korkusunun tıkınırcasına izleme için aktif bir etken olduğuna dikkat çeker. Yeni ve değişken ortamlar, görüntüleyenlerin tıkınırcasına izleme yoluyla çok miktarda içerik tüketmesine olanak tanır ki bu bir şeyleri kaçırma korkusu olgusu ile ilişkilendirilir. Tıkınırcasına izlerken, anlatı içeriği değişmez, yine de izlenen anlatı miktarı, geçmiş medya yayın modellerine kıyasla hızlandırılabilir. TV içeriğine erişimin artması, insanların izledikleri ve izlemeyi nasıl seçtikleri konusunda da daha fazla güce sahip oldukları anlamına gelir.

Sonuçta Netflix, orijinal içerik üretme stratejisi ile beslediği tıkınırcasına izleme davranışını seyirciyi, platforma koşullandırmak için ustaca kullanır. Öte yandan bugün aşırı izlemenin var olduğu talebe bağlı video servisleri bu eylemin ilk ortaya çıtı̆̆ı DVD zamanlarından daha farklıdır. Sonuçta DVD setleri bir sezon yayınlandıktan bir süre sonra ve yüksek bir fiyat ile izleyiciye sunulurken sezonlar arası bekleme süreleri OTT platformlarında nispeten kısalabilir ama izleyiciye maliyeti açısından önemli ölçüde düşüktür.

Netflix’in alışageldik bir strateji olan geleneksel yayın planına karşı davranışı sadece izleme şeklinin değişimi ile sınırlı değildir. Şirketin bu kararı, gösterilerin hem yapısını hem de içeriğini etkilemiş, senaryo yazarlarının izleyicilerin dikkatini reklam araları ve bir haftadan ötekine geçişte korumak için kullandıkları özetleri, arkası yarınları ve benzer anlatı metotlarını sürüncemede bırakmasına izin vermiştir. ${ }^{77}$ Matrix’e göre ${ }^{78}$ izleyicilerin arka arkaya, reklamsız TV eğlenceleri için artan tercihi, mevcut şovların yeni ve gelecek sezonları için senaryo yazımını ve pazarlama stratejilerini en az üç düzeyde etkilemektedir. İlk etki hikâye anlatımlarında görünür. Hikayeler, izleyicilerin bölümlerin önemsiz ayrıntılarını takip etmelerini gerektiren gömülü ipuçlarıyla ve gizemlerle dolu daha karmaşı entrika çizgileri içermektedir. İkinci etki yapım süreleri ile ilgilidir. Daha kısa dikkat süreleri daha kısa gösterilere yol açar. Öte yandan tıkınırcasına izleme (binge watching), geleneksel televizyon planlamasında tercih edilen yirmi iki bölüm yerine on ile on üç bölümlük sezonlara öncülük eder. Üçüncü ve son olarak seri izleme potansiyeli, yayıncılar tarafından bir programın diğer programlara nazaran daha fazla desteklenme potansiyeli doğurabilir.

Reklamlarla bölünmeyen bir izleme deneyimi olarak tıkınırcasına izleme, aynı zamanda izleyenin özerk zamanlama özgürlüğü ve zaman kaydırma teknolojileri ile de ilişkilendirilir. VOD ve DVD, içeriğin daha uygun bir zamanda izlenmesi için kaydedilmesine izin vermenin ötesindedir ve takip edilmesi gereken bir zamanı da asla dikte etmez. Listeleme sürecinde sonuçlar algoritmaya bağlı önerileri içerir, ancak ne zaman ne izleneceği tamamen izleyiciye bırakılır. Böylece izleme kişisel planlama

75 Sung, Kang ve Lee, "Why Do We Indulge?".

76 Lindsey Conlin, Andrew C. Billings ve Lauren Auverset, “Time-shifting vs. Appointment Viewing: The Role of Fear of Missing Out Within TV Consumption Behaviors”, Communication \& Society, 29 (2016), s.151.

77 Blake Hallinan ve Ted Striphas, "Recommended for You", s.129.

78 Matrix, “The Netflix Effect”, s.131. 
ve kişinin ruh hali ile şekillenir. Planlı bir TV akışı bu tür bir izleyici bağımsızlığına izin vermez. ${ }^{79}$ Son olarak TV reklam verenleri için Netflix'in getirdikleri, yeni reklam metotları geliştirme olarak karşımıza çıkar. Netflix, reklam verenlerden öteye abonelerinin istek ve arzuları ile ilgilidir. Arkadaştan arkadaşa dayanan öneriler, sosyal konuşmalar ve bunun tetiklediği bir şeyleri kaçırma dürtüsü ile aşırı değerlenen TV şovları, genellikle reklam içermez. Bu bağlamda Y ve Z jenerasyonundan oluşan Netflix kitlelerine ulaşmak isteyen pazarlamacılar için zorluk, marka sponsorlukları ve ürün yerleştirmeleri için izleyicilere doğal gelecek yeni yöntemler bulmaktır. ${ }^{80}$

\section{Sonuç}

İnternette video akışlarının tüketiciler için yarattığı çok seçenekli ortam, aynı zamanda geleneksel yayın planı ve içerik sahipliğinden kaynaklı kıtlık biçimlerinden farklı yapısıyla da dikkat çekicidir. Birçok araştırma, özellikle gelişmiş coğrafyalarda geniş içerik kütüphanelerinin ücretli/ücretsiz kataloglarına artan talebe ve buralara kayan video içerik tüketim alışkanlıklarına dikkat çekmektedir.

$\mathrm{Bu}$ tüketimin en belirgin olduğu OTT servisleri ise talebe bağlı video hizmetlerine olan ilginin yayılmasında öncü durumdadır. Öte yandan OTT’nin bir hizmet çeşidi olduğu ve sürekli birbirine karıştırıldığı VOD çatısı altında bir iş modeli olduğu unutulmamalıdir.

OTT, bir ISS'den bağımsız bir servis olarak kullanıcının farklı cihazlarda ve farklı geniş bant abonelikleri ile ulaşabileceği, geniş içerik kütüphanesi, talebe bağlı video hizmet mantığı ile sunulan bir hizmet şeklidir. Öte yandan farklı tip iş modelleri ile kategorize olan OTT'nin günümüzde bu kadar popüler olması, abonelik temelli bir talebe bağlı hizmet (SVOD) servisi olan Netflix’in küresel bir oyuncu olarak televizyon sektöründe hem üretim hem de tüketim bağlamında birçok yeniliği getirmesine bağlanabilir. Kısaca Netflix etkisi olarak da bilinen bu yenilikler ve etkileri şu şekilde özetlenebilir: Yerleşik TV paradigmalarının sorgulanması, İçerik üreticileri için yeni gelir kaynakları, abonelik temelli servislerin küresel pazara hakimiyeti, Tıkınırcasına İzleme.

Yerleşik televizyon paradigmaları sorgulanmaktadır. Televizyon kuruluşları için ellerindeki kitleyi ve bu kitleyi pazarladıkları reklam verenler ile iş birliklerini korumak bir sorun haline gelmiştir. Akışın bir sonucu olan parçalanmış izler kitlenin, sektörün yerleşik teamüllerine meydan okuyan akış içerik ve yayın planlamaları ile OTT servislerine doğru hareketlenmesi bu servislerin sunduğu hizmetlere benzer uygulamaları geleneksel yayıncılar için de bir gereklilik haline getirmektedir.

Ürün dağıtım biçimlerindeki çeşitlenme özellikle içerik üreticileri için pazarların ve bu pazarlardan elde edilecek katma değerin çeşitlenmesi anlamına gelmektedir. Pencereleme modeli bağlamında dile getirilen bu değişim aynı zamanda daha önce görmeye alışık olmadığımız yüksek bütçeli TV dramalarının da kapısını aralamıştır. OTT servisleri marka değerlerini güçlendirmek ve bir pazarlama stratejisi olarak ori-

79 Jenner, "Binge-watching", s.308.

80 Matrix, “The Netflix Effect”, s.132. 
jinal içerik üretimine önem vermektedir. Tüm değişimlere karşın içeriğin kral olarak kaldığı yeni televizyon yayıncılık düzeninde çeşitlilik ve ölçek platform aracılı pazarlarda rekabet etmenin temel ilkesini oluşturmaktadır. Gerek kataloğun zenginliği gerekse de orijinal içeriğe gösterilen önem üretim bütçelerine yansımaktadır. Ancak geleneksel ve yeni oyuncular arasındaki rekabette geleneksel TV kuruluşlarının bütçeleri ile bu tür bir yarışa girmesi de sağlıklı görülmez. Öte yandan uzun süredir reklam gelirlerine dayalı bir ekonomi üzerinde ilerleyen TV yayıncılığı, abonelik temelli servislerin küresel hakimiyetine tanık olmaktadır.

Abonelik temelli servislerin küresel hakimiyeti IP TV ya da uydu platformlarının ötesinde internet üzerinden ulaşılabilen içerik kütüphaneleri ile OTT servislerince sağlanıyor görünmektedir. Zira çalışmanın ilgili bölümünde de değinildiği üzere IPTV, yerel servis sağlayıcıların kontrolünde olan kapalı bir sistem olarak kurgulanmıştır. Keza abonelik tabanlı uydu ya da kablolu platformlar da OTT servislerinin sundukları karşısında yeterli cevap vermemekle birlikte yine mekân ve araçsal bağımlılıkla sinırlıdır.

Bir iş modeli olarak OTT, kendi katma değerini oluşturabilmek adına video akış teknolojilerinin getirdiği değişimleri yeniden işlemek eğilimi göstermektedir. Geleneksel televizyon yayın akışının sınırlılıklarına karşı her yerde istediği içeriği istediği ekran ile kullanıcılarına sunma vaadinde olan OTT servislerinin yıkıcı etkisi özellikle yayın planlama ve izleyici davranışlarında görülür. Kullanıcılarından elde ettiği veriler 1şı̆̆ında Netflix, bir dizinin tüm sezonunu tek seferde içerik kütüphanesine eklemektedir. Bu bir bakıma tıkınırcasına izlemek olarak tanımlanan (binge watching) aşırı izleme davranışını da destekleyen bir harekettir. Her ne kadar televizyonda maraton izleme deneyimi ile benzeşse de tıkınırcasına izleme davranışı talebe bağlı video iş akışları üzerinde yükselen OTT sektörünün çıkarlarına hizmet eder. Sonuçta bu tür bir davranışa uygun yayın planı, haftalık olarak beklemekten keyif almayan ve türlü uyaranlar ile çevirili yeni tip izleyiciyi elde tutabilmek için güçlü bir strateji gibi görünmektedir.

Sonuç olarak, Netflix, akışlı video pazarındaki en baskın oyuncu olmaya devam ederse, şirketin pazarlama stratejileri TV’nin endüstriyel uygulamalarını yeniden tanımlamaya devam edecek gibi görünmektedir.

\section{Kaynakça}

Banerjee, Aniruddha, James Alleman ve Paul Rappoport. "Video-Viewing Behavior in the Era of Connected Devices". Communications \& Strategies. 92 (2013): 1942.

Bondad-Brown, Beverly A., Ronald E. Rice ve Katy E. Pearce. "Influences on TV Viewing and Online User-shared Video Use: Demographics, Generations, Contextual Age, Media Use, Motivations, and Audience Activity". Journal of Broadcasting \& Electronic Media. 56/4 (2012): 471-493.

Chamberlain, Daniel. “Television Interfaces”. Journal of Popular Film and Television. 38/2 (2010): 84-88. 
Clipbucket. "Unterstanding the Difference between VOD and OTT". Erişim 17 Mart, 2019. https://clipbucket.com/2019/03/07/understanding-the-terms-svod-avodtvod-and-the-difference-between-vod-and-ott/.

Conlin, Lindsey, Andrew C. Billings ve Lauren Auverset. "Time-shifting vs. Appointment Viewing: The Role of Fear of Missing Out Within TV Consumption Behaviors". Communication \& Society. 29 (2016): 151-164.

Cox, Christopher M. "Programming - Flow in the Convergence of Digital Media Platforms and Television". Critical Studies in Television. 13/4 (2018): 438-454.

Demirkıran, Cenk. "Geleneksel Televizyonun Sanal Modeli Olarak Web Tv ve Livestream Portalında TV Yönetimi”. Akdeniz Üniversitesi İletişim Fakültesi Dergisi. 14 (2010): 73-85.

Dhoest, Alexander ve Nele Simons. "Still 'Watching' TV? The Consumption of TV Fiction by Engaged Audiences". Media and Communication. 4 (2016): 176-184.

Doyle, Gillian. "Digitization and Changing Windowing Strategies in the Television Industry: Negotiating New Windows on the World". Television \& New Media. 17/7 (2016): 629-645.

Ellis, Katie, Mike Kent, Kathryn Locke ve Ceridwen Clocherty. "Access for Everyone? Australia's 'Streaming Wars' and Consumers with Disabilities". Continuum. 31/6 (2017): 881-891.

Gilbert, Anne. "Push, Pull, Rerun: Television Reruns and Streaming Media". Television \& New Media. 20/7 (2019): 686-701.

Gimpel, Gregory. "The Future of Video Platforms: Key Questions Shaping the TV and Video Industry". International Journal on Media Management. 17 (2015): 25-46.

Herbert, Daniel, Amanda D. Lotz ve Lee Marshall. "Approaching Media İndustries Comparatively: A Case Study of Streaming". International Journal of Cultural Studies. 22/3 (2019): 349-366.

Hallinan, Blake ve Ted Striphas. "Recommended for You: The Netflix Prize and the Production of Algorithmic Culture". New Media \& Society. 18/1 (2016): 117-137.

Jang, Shinjae ve Minsoo Park. "Do New Media Substitute for Old Media?: A Panel Analysis of Daily Media Use". Journal of Media Economics. 29/2 (2016): 73-91.

Jenner, Mareike. "Is This TVIV? On Netflix, TVIII and Binge-watching". New Media \& Society. 18/2 (2016): 257-273.

Jenner, Mareike. "Binge-watching:Video-on-demand, QualityTV and Mainstreaming Fandom”. International Journal of Cultural Studies. 20/3 (2017): 304-320.

Johnson, Catherine. "Beyond Catch-up: VoD Interfaces, ITV Hub and the Repositioning of Television Online". Critical Studies in Television. 12/2 (2017): 121-138.

Lobato, Ramon. "Rethinking International TV Flows Research in the Age of Netflix". Television \& New Media. 19/3 (2018): 241-256. 
Matrix, Sidneyeve. “The Netflix Effect: Teens, Binge Watching, and On-Demand Digital Media Trends”. Jeunesse: Young People, Texts, Cultures. 6/1 (2014): 119138.

McKelvey, Fenwick ve Robert Hunt. "Discoverability: Toward a Definition of Content Discovery Through Platforms". Social Media + Society. 5/1 (2019): 1-15.

Moe, Hallvard, "Television, Digitalisation and Flow: Questioning the Promises of Viewer Control, Digital Utopia in the Media: From Discourses to Facts. A Balance". Proceedings of the III International Conference on Communication and Reality. Haz., Pere Masip ve Josep Rom. Barcelona: Facultat de Cièències de la Comunicació Blanquerna, 2005: 773-784.

OECD. “OECD Stat”. Erişim 05 Ekim, 2020, https://stats.oecd.org/.

Özel, Sedat. "Yeni Medya Çağında Radyoların Dönüşümü”. Akdeniz İletişim. 22 (2014): 168-189.

Özel, Sedat. "Bir Yayın Platformu Olarak İnternette Çevrim İçi Videolar ve Kullanıcılarının Doyum Faktörleri”. Global Media Journal. 5 (2015): 288-316.

Roberts, Chris ve Vince Muscarella. "Defining Over-The-Top (OTT) Digital Distribution". The Entertainment Merchants Association. (erişim 06.05.2020).

Sanson, Kevin ve Gregory Steirer. "Hulu, Streaming, and the Contemporary Television Ecosystem”. Media, Culture \& Society. 41/8 (2019): 1210-1227.

Schweidel, David A. ve Wendy W. Moe. "Binge Watching and Advertising”. Journal of Marketing. 80/5 (2016): 1-19.

Sørensen, Inge Ejbye. "The Revival of Live TV: Liveness in a Multiplatform Context”. Media, Culture \& Society. 38 (2015).

Sung, Yoon Hi, Eun Yeon Kang ve Wei-Na Lee. "Why Do We Indulge? Exploring Motivations for Binge Watching". Journal of Broadcasting \& Electronic Media. 62 (2018): 408-426.

Tefertiller, Alec. "Media Substitution in Cable Cord-Cutting: The Adoption of WebStreaming Television". Journal of Broadcasting \& Electronic Media. 62 (2018): 309-407.

Wayne, Michael L. "Netflix, Amazon, and Branded Television Content in Subscription Video On-Demand Portals". Media, Culture \& Society. 40/5 (2018): 725-741. 
İNSAN\&İNSAN, Y11/Year 7, Sayı/Issue 26, Güz/Fall 2020, 115-138

DOI: https://doi.org/10.29224/insanveinsan.786938

\title{
The Netflix Effect in the Age of Video on Demand Services
}

SEDAT ÖZEL

\begin{abstract}
The emergence and development of video streaming technology has been the reason for a strong change in traditional television production and consumption forms. An active viewing process for the audience is frequently mentioned, also new opportunities and new business models in the distribution of television content are emphasized. The study focuses on OTT, one of these business models, together with It examines the basic codes of change adhering to a conceptual analysis. The Netflix effect statement is often used to describe this change. In this context, the determinations of how Netflix stands out are at some point a concrete example of the change in television. Netflix has grown globally with developing content catalogs that fit the fragmented structure of the audience, implementing its own broadcast plan against the standard television stream, and strategies that support the binge watching behavior associated with them.
\end{abstract}

Keywords: Video streaming, OTT, Video on demand, Binge watching, Netflix 